\title{
CLINICAL USES OF 2,3-DIMERCAPTOPROPANOL (BAL). II. THE EFFECT OF BAL ON THE EXCRETION OF ARSENIC IN NORMAL SUBJECTS AND AFTER MINIMAL EX- POSURE TO ARSENICAL. SMOKE
}

\author{
By J. WEXLER, ${ }^{1}$ H. EAGLE, H. J. TATUM, ${ }^{2}$ H. J. MAGNUSON and E. B. WATSON \\ (From the Clinical Research Section, Medical Division, Chemical Warfare Service, U. S. Army \\ and the Venereal Disease Research Laboratory of the United States Public Health \\ Service, Johns Hopkins Hospital, Baltimore)
}

(Received for publication February 5, 1946)

It has been shown by several investigators $(1$, 2) that "BAL" (2,3-dimercaptopropanol) accelerates the excretion of arsenic in experimental animals poisoned with various arsenicals.

In man also, the cutaneous application of BAL ointment (3) or the intramuscular injection of a solution in peanut oil and benzyl benzoate $(4,5)$ in cases of arsenical dermatitis sometimes results in an increased urinary arsenic excretion, as determined by analyses on 12 - to 24 -hour specimens collected before and after its administration. In view of the short-lived effect of BAL in experimental animals, it is possible that these effects of BAL on urinary arsenic excretion in man would have been more pronounced and more regular had it been possible to obtain urine specimens at 2 - to 4-hour intervals.

The present paper represents an attempt to determine the effect of BAL on the normal urinary arsenic excretion in man, as compared with its effect in human subjects exposed for brief intervals to minimal concentrations of an arsenical smoke (diphenylcyanoarsine). By treating the latter group at varying intervals after exposure and by obtaining urine specimens at 2 -hour intervals, it was hoped to delimit somewhat more precisely its effect on the urinary excretion of arsenic, and to ascertain whether BAL could be used to confirm suspected minimal exposure to arsenical poison gases. The results might be of significance also in relation to the detection and prevention of industrial arsenic poisoning.

\section{METHODS}

\section{Normal controls.}

Six normal young soldiers served as controls. On the morning of the test, after breakfast, bladders were emp-

$$
\text { 1, } 2 \text { Capt., M.C. }
$$

tied at 8 a.m. No cigarettes or solid food were allowed during the following 12-hour experimental period. Two hundred ml. of $\mathrm{H}_{2} \mathrm{O}$ were thereafter taken by mouth each hour, and $500 \mathrm{ml}$. of milk at $12 \mathrm{~m}$., and again at 5 p.m.

Urine specimens were collected every 2 hours into Erlenmeyer flasks cleaned with arsenic-free acid. At the end of the third 2-hour period, each man was injected intramuscularly with $3.5 \mathrm{mgm}$. of BAL per $\mathrm{kgm}$. body weight, administered as a 10 per cent solution in peanut oil with 20 per cent benzyl benzoate as a solubilizing agent (2). Following treatment, the urine was again collected every 2 hours for 6 hours. There were thus a total of 62 -hour specimens on each volunteer, 3 before and 3 after the injection of BAL.

The arsenic content of the individual specimens was determined by the method of Magnuson and Watson (6). The milk was analyzed and found to be arsenic-free (less than 0.01 micrograms per $\mathrm{ml}$.).

\section{Exposure of men to diphenylcyanoarsine (D.C.) smoke.}

Twelve men were exposed in a gas chamber for 6 minutes to diphenylcyanoarsine smoke, at a total arsenic concentration of $3.9 \mathrm{mgm}$. per cu.m. Of this, $1.6 \mathrm{mgm}$. was present as diphenylcyanoarsine, $0.5 \mathrm{mgm}$. as other forms of organic arsenic, and $1.8 \mathrm{mgm}$. as inorganic arsenic.

The exposed men were then divided into 4 groups of 3 men each. Studies similar to those carried out on the 6 normal controls were carried out on one group of 3 men beginning $1 / 2$ hour after exposure, on a second group 24 hours after exposure, on a third 48 hours after exposure, and on the last group of 3 men 72 hours after exposure. The 4 groups therefore received their BAL $61 \frac{1}{2}, 30,54$ and 78 hours after exposure.

Ten of the 18 injections of BAL were followed by a rise in blood pressure, which returned to normal within 2 hours. Eleven of the BAL injections gave rise to mild to moderate symptoms consisting of nausea, sense of burning in mouth and face, a dry, peppery taste in mouth and salivation. These symptoms disappeared within 2 hours. Significant but temporary local pain followed all injections. The incidence of these symptoms was higher than those reported by other investigators $(7,4)$ in men injected with a dose of $4 \mathrm{mgm}$. per $\mathrm{kgm}$. In no instance, 
TABLE I

Urinary arsenic excretion in 6 normal men

\begin{tabular}{|c|c|c|c|c|c|c|c|c|}
\hline \multirow{3}{*}{ Subject } & \multicolumn{4}{|c|}{ Before injection of BAL } & \multicolumn{4}{|c|}{ After injection of BAL } \\
\hline & \multicolumn{4}{|c|}{ 2-Hourly excretion of arsenic } & \multicolumn{4}{|c|}{ 2-Hourly excretion of arsenic } \\
\hline & -6 to -4 & -4 to -2 & -2 to 0 & Average & 0 to 2 & 2 to 4 & 4 to 6 & Average \\
\hline $\begin{array}{l}\mathrm{Bu} \\
\mathbf{C a} \\
\mathrm{Ch} \\
\mathrm{De} \\
\mathbf{G r} \\
\mathbf{W i}\end{array}$ & $\begin{array}{c}\text { mmg. } \\
5.2 \\
4.0 \\
2.6 \\
1.9 \\
4.4 \\
2.0\end{array}$ & $\begin{array}{c}m m g . \\
6.6 \\
3.9 \\
3.5 \\
3.9 \\
5.3 \\
3.3\end{array}$ & $\begin{array}{c}\text { mmg. } \\
6.9 \\
7.6 \\
2.3 \\
2.6 \\
4.3 \\
3.2\end{array}$ & $\begin{array}{c}\text { mmg. } \\
6.2 \\
5.2 \\
2.8 \\
2.8 \\
4.7 \\
2.9\end{array}$ & $\begin{array}{c}\text { mmg. } \\
7.0 \\
5.0 \\
4.2 \\
2.9 \\
6.0 \\
4.6\end{array}$ & $\begin{array}{c}m m g . \\
9.3 \\
5.2 \\
4.8 \\
4.4 \\
4.1 \\
5.3\end{array}$ & $\begin{array}{c}m m g . \\
7.3 \\
3.7 \\
2.9 \\
3.5 \\
2.9 \\
5.1\end{array}$ & $\begin{array}{c}\text { mmg. } \\
7.9 \\
4.6 \\
4.0 \\
3.6 \\
4.3 \\
5.0\end{array}$ \\
\hline Average & 3.3 & 4.4 & 4.5 & 4.1 & 4.9 & 5.5 & 4.2 & 5.0 \\
\hline
\end{tabular}

however, were the symptoms sufficiently severe to have contraindicated a repeat injection.

\section{EXPERIMENTAL RESULTS}

\section{Normal controls.}

The analytical results in the 6 normal controls are given in detail in Table $I$. They are graphically shown in Figure 1, in which the excretion in each 2-hour period after the injection of BAL has been plotted relative to the average 2-hourly excretion for that individual prior to the administration of BAL.

It is evident that in 5 of the 6 subjects, the injection of BAL caused a definite if slight increase in the normal arsenic excretion. In 4 of the 5 the excretion reached its maximum in the second 2-hour period after the administration of $\mathrm{BAL}$, and the increase was no longer apparent in the third 2-hour period.

The average absolute increase in arsenic excretion was 0.9 micrograms (standard error 0.1 ) in the first 2-hour period, 1.4 micrograms (standard error 0.6 ) in the second, and 0.2 micrograms (standard error 0.7 ) in the third. The average percentage increase in excretion was 20 in the first 2 -hour period, 37 in the second, and 2 per cent in the third. The changes in the first 2 periods after the administration of BAL, although small, are nevertheless significant.

\section{Men exposed to diphenylcyanoarsine.}

The 12 men exposed to diphenylcyanoarsine were divided into 4 groups of 3 each, which were treated with BAL at different times after exposure. The analytical data with respect to arsenic excretion are given in Tables II and III.

The average 2-hour urinary excretion of arsenic $1 / 2,24$, 48 and 72 hours after exposure to diphenylcyanoarsine was 13.3, 13.6, 7.8 and 6.0 micrograms respectively (Table II), as compared with a level of 4.1 in a control group of normal subjects not exposed to the arsenical smoke. The administration of BAL in each of these groups was regularly followed by an increased urinary excretion of arsenic, reaching its maximum in 9 of the 12 subjects in the second rather than the first 2-hour period. In all but 3 of the 12 subjects the effect of BAL had essentially worn off in 4 hours, and in 6 of the 12, the third 2-hour period actually showed a decreased rather than increased excretion as compared with the average 2-hour excretion before BAL.

The absolute increase in micrograms excreted per 2hour period was maximal in those treated with BAL $61 / 2$ hours after exposure, where it averaged 5.2, 9.0 and 3.3 in 3 successive 2-hour specimens (Table III). In those treated 30 hours after exposure, the corresponding values were +4.9 , +4.7 , and -2.8 (i.e., an actual decrease in the last 2-hour period) ; 54 hours after exposure the effect of BAL was even less, the increase averaging 1.8, 1.9 and 1.8 micrograms respectively; and 78 hours after exposure the change caused by BAL was $+2.2,+2.7$, and -0.4 micrograms in 3 successive 2-hour specimens. When the results were expressed on a percentage basis (Figure 3 ), and referred to the average excretion immediately preceding the administration of BAL as 100 , it was found that the injection of BAL at $61 / 2$ hours after exposure was followed by a percentage increase of 39 , 68 , and 25 per cent in 3 successive 2 -hour specimens. When treatment was delayed for 30 hours after exposure, the corresponding values were $+20,+19$ and -20 per cent. In subjects treated 54 hours after exposure, there was an increase of 23,24 , and 23 per cent in 3 successive 2-hour specimens; and the corresponding values in these treated 78 hours after exposure were $+37,+45$ and -7 per cent. These figures are to be compared with the percentage changes of $+20,+37$, and +2 per cent in 6 normal subjects similarly treated.

The analytical data are graphically summarized in Figures 2 and 3. Each curve in those figures refers to a group of 3 subjects treated with BAL, at varying times after exposure, and each point on the curves is the aver- 


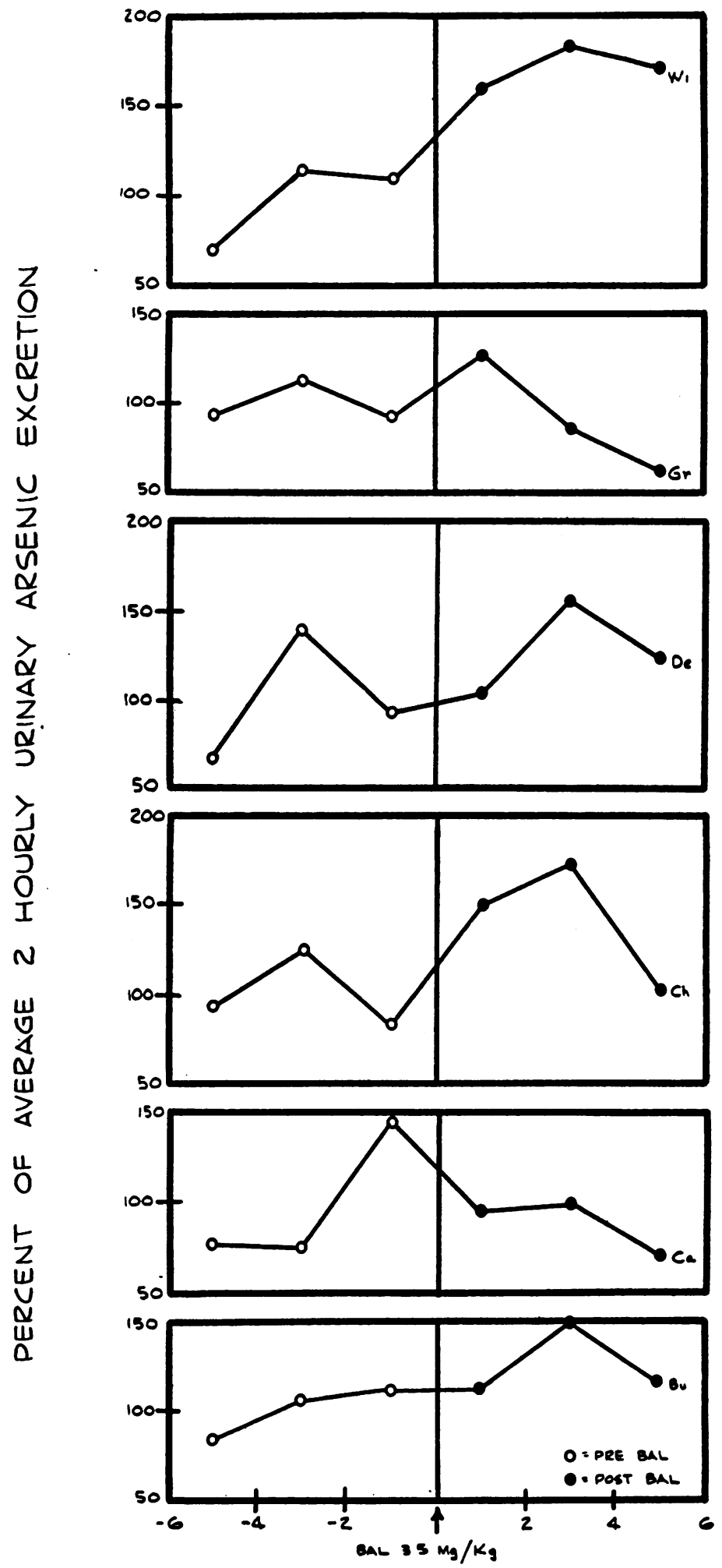

HOURS OF COLLECTION

Fig. 1. The Effect of a Single Intramuscular Injection of BAL (3.5 mgm. per kgm.) on the Urinary ExCREtion of Arsenic in 6 Normal Subjects

The excretion in 3 successive 2-hourly periods immediately preceding the administration of BAL was averaged, and the data of Table I referred to that average as 100 per cent. 
TABLE II

Urinary arsenic excretion in 12 men exposed to diphenylcyanoarsine smoke

\begin{tabular}{|c|c|c|c|c|c|c|c|c|c|c|}
\hline \multirow{3}{*}{ Group } & \multirow{3}{*}{$\begin{array}{l}\text { Time after ex- } \\
\text { posure at start } \\
\text { of experi- } \\
\text { mental period }\end{array}$} & \multirow{3}{*}{ Subject } & \multicolumn{4}{|c|}{ Before injection of BAL } & \multicolumn{4}{|c|}{ After injection of BAL } \\
\hline & & & \multicolumn{4}{|c|}{ 2-Hourly excretion of arsenic } & \multicolumn{4}{|c|}{ 2-Hourly excretion of arsenic } \\
\hline & & & -6 to -4 & -4 to -2 & -2 to 0 & Average & 0 to 2 & 2 to 4 & 4 to 6 & Average \\
\hline I & $\begin{array}{c}\text { hours } \\
\frac{1}{2}\end{array}$ & $\begin{array}{l}\text { Gu } \\
\text { Ho } \\
\text { On } \\
\text { Average }\end{array}$ & $\begin{array}{c}\text { mmg. } \\
13.0 \\
14.8 \\
13.2 \\
13.7\end{array}$ & $\begin{array}{c}\text { mmg. } \\
11.2 \\
15.0 \\
11.0 \\
12.4\end{array}$ & $\begin{array}{r}\text { mmg. } \\
14.6 \\
16.7 \\
9.7 \\
13.9\end{array}$ & $\begin{array}{c}\text { mmg. } \\
12.9 \\
15.6 \\
11.3 \\
13.3\end{array}$ & $\begin{array}{c}\text { mmg. } \\
10.4 \\
30.4 \\
14.6 \\
18.5\end{array}$ & $\begin{array}{l}\text { mmg. } \\
17.2 \\
31.2 \\
18.4 \\
22.3\end{array}$ & $\begin{array}{c}\text { mmg. } \\
14.0 \\
22.0 \\
11.8 \\
15.9\end{array}$ & $\begin{array}{c}\text { mmg. } \\
13.9 \\
27.9 \\
14.9 \\
18.9\end{array}$ \\
\hline II & 24 & $\begin{array}{l}\mathrm{Ca} \\
\mathrm{Sh} \\
\mathrm{Te} \\
\text { Average }\end{array}$ & $\begin{array}{r}15.9 \\
7.3 \\
15.2 \\
12.8\end{array}$ & $\begin{array}{l}14.8 \\
10.4 \\
15.0 \\
13.4\end{array}$ & $\begin{array}{r}14.2 \\
9.3 \\
20.3 \\
14.6\end{array}$ & $\begin{array}{r}14.9 \\
9.0 \\
16.8 \\
13.6\end{array}$ & $\begin{array}{l}17.2 \\
11.5 \\
20.5 \\
16.4\end{array}$ & $\begin{array}{l}17.9 \\
13.2 \\
17.6 \\
16.2\end{array}$ & $\begin{array}{r}11.7 \\
8.1 \\
12.5 \\
10.8\end{array}$ & $\begin{array}{l}15.5 \\
10.9 \\
16.9 \\
14.5\end{array}$ \\
\hline III & 48 & $\begin{array}{l}\text { Bu } \\
\text { De } \\
\text { Gr } \\
\text { Average }\end{array}$ & $\begin{array}{r}10.8 \\
5.8 \\
8.2 \\
8.3\end{array}$ & $\begin{array}{l}9.9 \\
5.3 \\
8.4 \\
7.9\end{array}$ & $\begin{array}{l}9.7 \\
4.8 \\
6.9 \\
7.1\end{array}$ & $\begin{array}{r}10.1 \\
5.3 \\
7.8 \\
7.8\end{array}$ & $\begin{array}{r}12.2 \\
7.9 \\
8.8 \\
9.6\end{array}$ & $\begin{array}{r}10.2 \\
9.0 \\
9.8 \\
9.7\end{array}$ & $\begin{array}{r}8.8 \\
6.2 \\
13.9 \\
9.6\end{array}$ & $\begin{array}{r}10.4 \\
7.7 \\
10.8 \\
9.6\end{array}$ \\
\hline IV & 72 & $\begin{array}{l}\mathrm{Ca} \\
\text { Fo } \\
\text { Kr } \\
\text { Average }\end{array}$ & $\begin{array}{l}6.2 \\
5.9 \\
5.1 \\
5.7\end{array}$ & $\begin{array}{l}6.0 \\
6.0 \\
6.8 \\
6.3\end{array}$ & $\begin{array}{l}8.3 \\
4.3 \\
5.8 \\
6.1\end{array}$ & $\begin{array}{l}6.8 \\
5.4 \\
5.9 \\
6.0\end{array}$ & $\begin{array}{l}9.1 \\
8.3 \\
7.3 \\
8.2\end{array}$ & $\begin{array}{r}10.5 \\
8.7 \\
6.8 \\
8.7\end{array}$ & $\begin{array}{l}7.0 \\
5.5 \\
4.4 \\
5.6\end{array}$ & $\begin{array}{l}8.8 \\
7.5 \\
6.2 \\
7.5\end{array}$ \\
\hline
\end{tabular}

TABLE III

The increase in the urinary excretion of arsenic after a single intramuscular injection of $B A L$ (3.5 mgm. per $\mathrm{kgm}$.) in 12 men exposed to diphenylcyanoarsine smoke

(After data in Table II)

\begin{tabular}{|c|c|c|c|c|c|c|c|}
\hline \multirow{2}{*}{$\begin{array}{l}\text { Time between } \\
\text { exposure to } \\
\text { diphenylcyano- } \\
\text { arsine and in- } \\
\text { jection of BAL }\end{array}$} & \multirow{2}{*}{$\begin{array}{l}\text { 2-hourly urin- } \\
\text { ary arsenic } \\
\text { excretion be- } \\
\text { fore BAL* }\end{array}$} & \multicolumn{6}{|c|}{ Change in 2-hourly urinary arsenic excretion after injection of BAL } \\
\hline & & \multicolumn{2}{|c|}{ 1st post-BAL period } & \multicolumn{2}{|c|}{ 2nd post-BAL period } & \multicolumn{2}{|c|}{ 3rd post-BAL period } \\
\hline $\begin{array}{l}\text { hours } \\
6 \frac{1}{2} \\
30 \\
54 \\
78\end{array}$ & $\begin{array}{l}m m g . \\
13.3^{* *} \\
13.6 \\
7.8 \\
6.0\end{array}$ & $\begin{array}{l}m m g . \\
+5.2 \\
+2.8 \\
+1.8 \\
+2.2\end{array}$ & $\begin{array}{c}\text { per cent } \\
+39 \\
+20 \\
+23 \\
+37\end{array}$ & $\begin{array}{l}\text { mmg. } \\
+9.0 \\
+2.6 \\
+1.9 \\
+2.7\end{array}$ & $\begin{array}{l}\text { per cent } \\
+68 \\
+19 \\
+24 \\
+45\end{array}$ & $\begin{array}{l}m m g . \\
+3.8 \\
-2.8 \\
+1.8 \\
-0.4\end{array}$ & $\begin{array}{l}\text { per cent } \\
+25 \\
-20 \\
+23 \\
-7\end{array}$ \\
\hline
\end{tabular}

* Average of 3 successive 2-hour periods.

** This and all other values in table are average of 3 different subjects in each period.

age urinary arsenic excretion of those 3 subjects in a particular 2-hour period. In Figure 2 the results have been plotted in absolute terms, as micrograms of arsenic excreted. In Figure 3, the excretions have been plotted on a percentage basis, taking for the reference value of 100 the average of the three 2 -hour periods preceding the administration of BAL.

\section{DISCUSSION}

It has been shown that a single intramuscular injection of BAL at a dose of $3.5 \mathrm{mgm}$. per $\mathrm{kgm}$. increased the urinary arsenic excretion in 5 of 6 control subjects, and 11 of 12 men exposed for 6 minutes to a low concentration of diphenylcyanoarsine smoke. In no instance was the administration of BAL followed by a decreased excretion. In all groups, the maximum increment in urinary arsenic excretion occurred within the first 4 hours, and usually during the second 2-hour period after the injection of BAL. Thereafter, the rate of excretion decreased, so that the average excretion during the third 2-hour period after BAL was not significantly different from that in the 6-hour control period preceding its administration, and in 8 of the 18 subjects was actually less. 


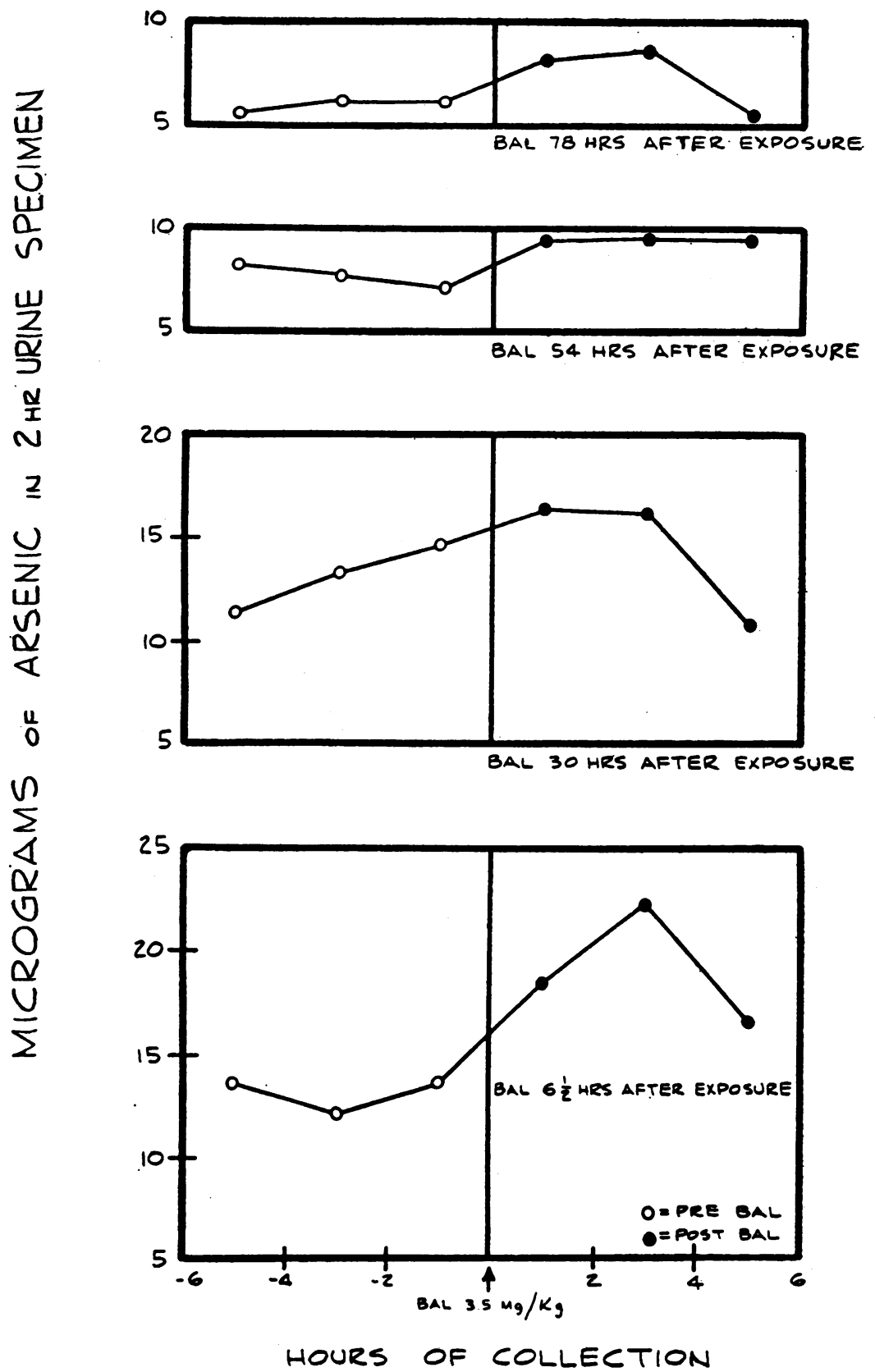

Fig. 2. The Effect of a Single Intramuscular Injection of BAL (3.5 mgm. Per Kgm.) on the Urinary Excretion of Arsenic in 12 Subjects Exposed to Diphenylcyanoarsine Smoke

Subjects were treated $61 / 2,30,54$, and 78 hours after exposure. Three urine specimens were collected at 2-hourly intervals for 6 hours before and after the administration of BAL. The plotted values are the average of 3 subjects in each group.

These results are qualitatively similar to those observed in rabbits $(2 \mathrm{~b})$. The increment in arsenic excretion here observed (up to 100 per cent, av- eraging approximately 40) did not even approach the 20 - to 130 -fold increase observed in rabbits poisoned with phenylarsenoxide or Lewisite (2, 


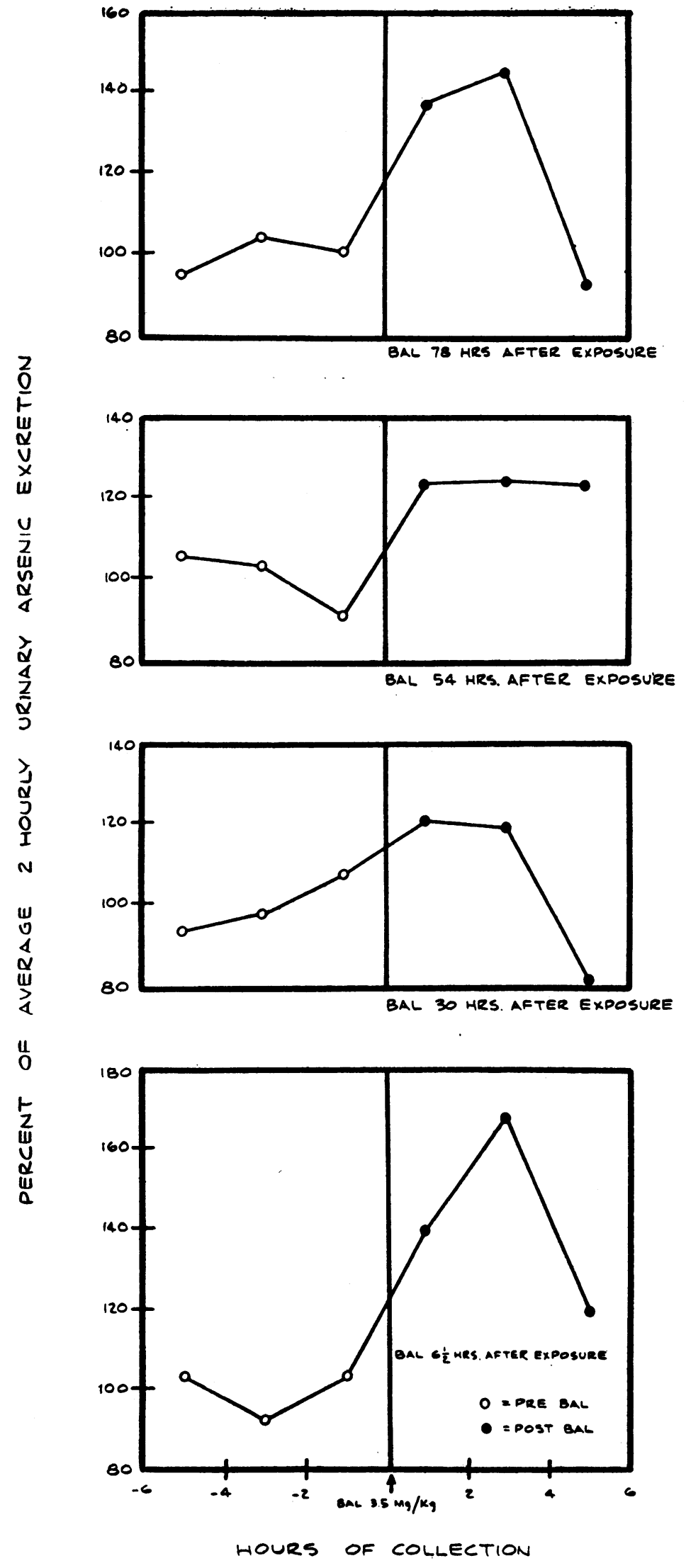


4). The difference may be referable to the larger doses of arsenical administered in the experimental animals ( 0.56 to $0.69 \mathrm{mgm}$. per $\mathrm{kgm}$.), the varying method of its administration (intramuscular or subcutaneous instead of by inhalation) and the larger doses of BAL employed (10 mgm. per $\mathrm{kgm}$. instead of $3.5 \mathrm{mgm}$. per $\mathrm{kgm}$.). Despite these differences, in man as in animals the effect of BAL on arsenic excretion had disappeared within 4 hours.

It follows from these observations that when solutions of BAL in peanut oil and benzyl benzoate are used therapeutically, the optimum interval to be allowed between injections, i.e., the longest interval which permits a continuous effect on arsenic excretion, is approximately 4 hours as originally recommended $(2,4)$. It follows, also, that the previously reported data with respect to the effect of BAL on the urinary excretion of arsenic in cases of arsenical dermatis, based on pooled 12- to 24-hour specimens, do not necessarily reflect the maximum effect of $B A L$ on the rate of that excretion. A similar series of patients should be studied on the basis of 2-hour specimens collected for a period of e.g. 6 hours before and 6 hours after a therapeutic injection of BAL.

It would appear from the data herein reported that the determination of the urinary arsenic is a simple and reliable criterion for the detection of abnormal exposure to arsenic in man. The effect of BAL in promoting excretion may be used as a supplementary procedure, of particular value if it is used soon after exposure.

\section{SUM MARY}

1. In 12 men exposed for 6 minutes to minute concentrations of an arsenical smoke, there was an immediate increase in the urinary excretion of arsenic, which gradually fell thereafter from an

Fig. 3. The Effect of a Single Intramuscular INJECTION OF BAL (3.5 MGM. PER KGM.) ON THE URINARY Excretion of Arsenic in 12 Subjects Exposed to Diphenylcyanoarsine Smoke

Subjects were treated $61 / 2,30,54$, and 78 hours after exposure. The excretion in 3 successive 2-hourly periods immediately preceding the administration of BAL were averaged for each group of 3 subjects, and the data of Table II referred to that average as 100 per cent. initial average of 6.8 micrograms per hour to an average of 3 micrograms per hour 72 hours after exposure. The corresponding value in a group of 6 control subjects was 2 micrograms per hour.

2. In both groups, those exposed to arsenic as well as the normal controls, a single intramuscular injection of BAL at a dose of $3.5 \mathrm{mgm}$. per $\mathrm{kgm}$. administered as a 10 per cent solution in peanut oil and benzyl benzoate, was followed by a significant and regular increase in the rate of urinary arsenic excretion. The effect usually reached a maximum within 2 to 4 hours, and was usually not demonstrable thereafter. The largest increase; both absolute and relative, was observed in the group of subjects treated with BAL soon (61/2 hours) after exposure to the arsenical smoke.

3. The significance of these observations with respect to the optimum time interval between successive therapeutic injections of BAL, and its use to detect abnormal exposure to arsenic, are discussed in the text.

\section{BIBLIOGRAPHY}

Note: Some of the investigations here included as references (*) have not yet been published in the open literature. The date given is the year in which the study was carried out.

1. Waters, L. L., and Stock, C. C., BAL (British AntiLewisite). Science, 1945, 102, 601.

*2a. Eagle, H., 1943, 1944.

2b. Eagle, H., Magnuson, H. J., and Fleischman, R., The systemic treatment of experimental arsenic poisoning (mapharsen, Lewisite, phenylarsenoxide), with BAL. J. Clin. Invest., 1946, 25, 451.

3. Luetscher, J. A., Eagle, H., and Longcope, W. T., The effect of BAL on the excretion of arsenic in arsenical intoxication. J. Clin. Invest., 1946, 25, 534.

*4a. Eagle, H., Magnuson, H. J., and Fleischman, R., $1943,1944$.

4b. Eagle, H., and Magnuson, H. J., The systemic treatment of 227 cases of arsenic poisoning (encephalitis, dermatitis, blood dyscrasias, jaundice, fever) with 2,3-dimercaptopropanol ("BAL"). Am. J. Syph., in press.

*5. Riker, W. F., and McDermott, W., 1944.

6. Magnuson, H. J., and Watson, E. B., Microdetermination of arsenic in biological materials. Indust. and Eng. Chem., 1944, 16, 339.

7. Sulzberger, M. B., Baer, R. L., and Kanof, A., Studies on the toxicity of BAL on percutaneous and parenteral administration. J. Clin. Invest., 1946, 25, 474. 